\title{
Guidelines for the design of a healing garden for the rehabilitation of psychiatric patients
}

\author{
Chantal Erbino, Alessandro Toccolini, Ilda Vagge, Paolo Stefano Ferrario \\ Department of Agricultural and Environmental Sciences, University of Milan, Italy
}

\begin{abstract}
Healing gardens are green spaces designed to promote and improve health and well-being for people suffering from illness. This paper proposes a methodology for defining a master plan for healing gardens. The methodology is based on site analysis (identification, limitations and potentials of the area) and the evaluation of user needs (patients, staff, relatives). The aim of the master plan is to provide guidelines for the definition of the executive plan, and to set up a sufficiently flexible project suitable for future new categories of patients, according to the different needs of the regional health authorities. The methodology has been applied to a case study: this paper considers the design of the healing garden of a building named Villa Bianca, part of the wider complex of the clinic for mental disorders Villa di Salute located in Trofarello (in the province of Turin, Piedmont, Italy). The main kinds of disturbances treated at Villa di Salute are schizophrenia and personality disorders; there are also some patients with severe depression. At the present time the building and the garden of Villa Bianca are not being used and are undergoing renovation.
\end{abstract}

\section{Introduction}

Healing gardens are green spaces designed to promote health and well-being and provide comfort for people suffering from illness. The concept of healing can be understood as a process that promotes wellbeing; it is important that the illness is cured (from a clinical point of view), but it is also important to try to help patients feel good

\footnotetext{
Correspondence: Alessandro Toccolini, Department of Agricultural and Environmental Sciences, University of Milan, via Celoria 2, 20133 Milan, Italy.

Tel.: +39.02.5031.6854 - Fax: +39.02 .5031 .6845 .

E-mail: alessandro.toccolini@unimi.it
}

Key words: Healing garden; design; horticultural therapy; psychiatric patients.

Received for publication: 22 July 2014.

Accepted for publication: 8 April 2015.

(C) Copyright C. Erbino et al., 2015

Licensee PAGEPress, Italy

Journal of Agricultural Engineering 2015; XLVI:426

doi:10.4081/jae.2015.426

This article is distributed under the terms of the Creative Commons Attribution Noncommercial License (by-nc 3.0) which permits any noncommercial use, distribution, and reproduction in any medium, provided the original author(s) and source are credited.
(Stigsdotter and Grahn, 2002). Clare Cooper Marcus (Cooper Marcus et al., 1995; Cooper Marcus, 2005a, 2005b, 2007) defines healing gardens as places where people can recover their health and mental and spiritual well-being, while reducing stress.

The benefits of a healing garden can be multiple (Cohen Mansfield and Werner, 1998; Küller and Wetterberg, 1996): stress reduction for patients, family and staff (Ulrich et al., 1991; Van Den Berg and Custers, 2011; Adevi and Lieberg, 2012); reductions in care costs (Ulrich, 2001, 2002); increased autonomy for patients (Namazi and Johnson, 1992; Seifert et al., 2005); improved mood (Rodiek, 2002) and quality of life (Stigsdotter et al., 2003; Varni et al., 2004; Sherman et al., 2005).

There are two research approaches to investigating the benefits that a healing garden has on human well-being. The first studies the benefits deriving from the contact between humans and nature; the second investigates how cultivating a garden can improve mental and physical well-being (Stigsdotter and Grahn, 2002). The second is an active approach, in which the benefits come from activities in the garden, such as maintenance or growing plants, vegetables and flowers (horticultural therapy). According to Cristina Borghi (Borghi, 2007, 2011), the two approaches are inseparable, because they work together to create harmony and physical and mental balance, expecially in the case of mental disorders.

In order to release stress and stop the patient thinking about his/her illness, the garden and its natural elements have to provide sensorial stimuli and facilitate psychological movement with vistas through a variety of spaces, such as lawns, tree-lined avenues, flowerbeds and shrubbery, thus stimulating the senses with different colours, forms and textures. For this reason, the choice of vegetation is a fundamental element in the garden design. Clare Cooper Marcus (Cooper Marcus et al., 1995) recommends choosing flourishing and colourful plants that are eye-catching and able to provide a lush and peaceful landscape. She proposes using flowering trees, shrubs and perennials that induce a sense of seasonal change. The careful choice of plants improves the quality of the project and the healing power of the garden. These principles inspire the research and designing of a healing garden for the clinic, with a view to the implementation of the rehabilitation program. This program includes some gardening activities, according to the principles that living outdoors is better than spending time in a closed room, and that manual works help healing much faster than just sitting and brooding.

\section{Study area}

The garden under study is that of a building currently not in use denominated Villa Bianca, part of the wider complex of the Villa di Salute clinic for mental disorders located in the municipality of Trofarello, $16 \mathrm{~km}$ from the city of Turin in the Piedmont region (Italy) (Figure 1). The municipality covers $12.3 \mathrm{~km}^{2}$ between the edge of the plain and the lower slopes of the Turin-Monferrino hill system and has a population of about 11,000 inhabitants (National Institute of Statistics - ISTAT, 2014).

The clinic Villa di Salute was founded in 1898 by Dr. Gaetano 
Demichelis, in a historic building in Trofarello. After the First World War, due to an increased demand for care the nearby building Villa Bianca was acquired, which in 1947 became part of the clinic. The healthcare activities in Villa Bianca are currently suspended and the building and the garden are undergoing renovation.

The study area (Figure 2) covers $4510 \mathrm{~m}^{2}$ at an altitude of $278 \mathrm{~m}$. The maximum difference in height within the area is about $2 \mathrm{~m}$; the western part is flat, and the eastern part is located at a higher level with a slight slope (about 1.5\%). The main axis of the area is oriented northwest/south-east; the area near the building was used as an ornamental garden, while the eastern area was used as an orchard and vegetable garden.

Currently the vegetation consists of trees (Cedrus atlantica glauca, Picea abies, Ulmus minor, Prunus armeniaca, Prunus domestica, Lagerstroemia indica, Ailanthus altissima), bushes and brambles, and includes a row of trees (Ulmus minor Mill.).

\section{Materials and methods}

The proposed methodology for the definition of the master plan is illustrated in Figure 3, and includes two preliminary analyses: of the site's characteristics and of potential users (Beer, 2000). Site analysis identifies the limits and potentialities of the area and zones suitable for specific activities; user analysis aims to identify the activities of
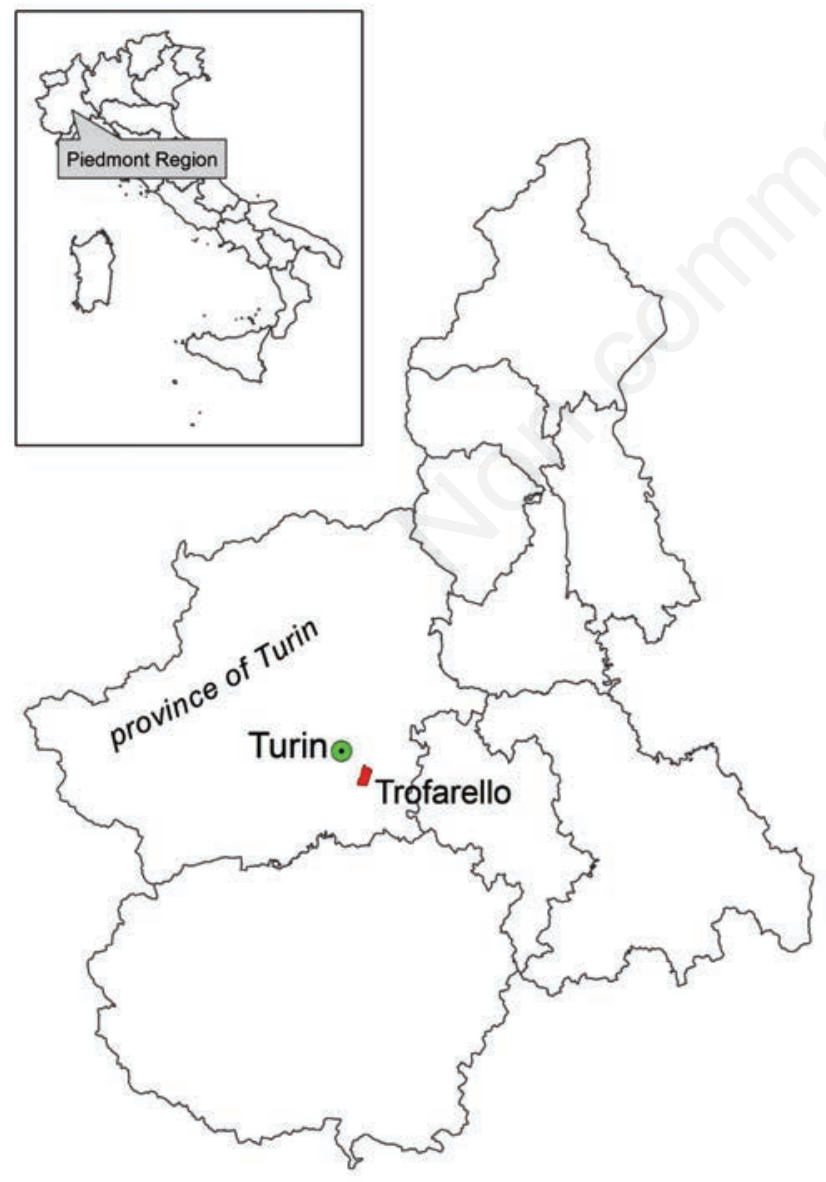

Figure 1. Piedmont region and municipality of Trofarello. patients, staff and relatives, and to define user needs. The two analyses contributed to defining first a concept plan for the area and then the master plan.

\section{Site analysis}

Site analysis includes investigation of characteristics such as orography and slopes, vegetation, land use, climate. In terms of climate, the site is in a temperate sub-continental area, with cold winters and warm

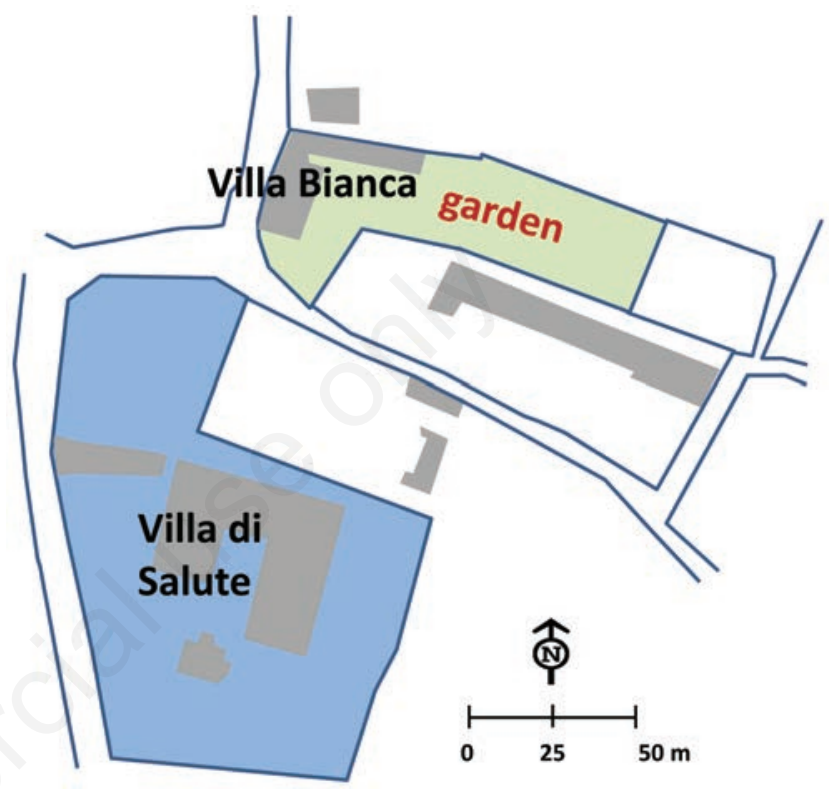

Figure 2. The studied garden.

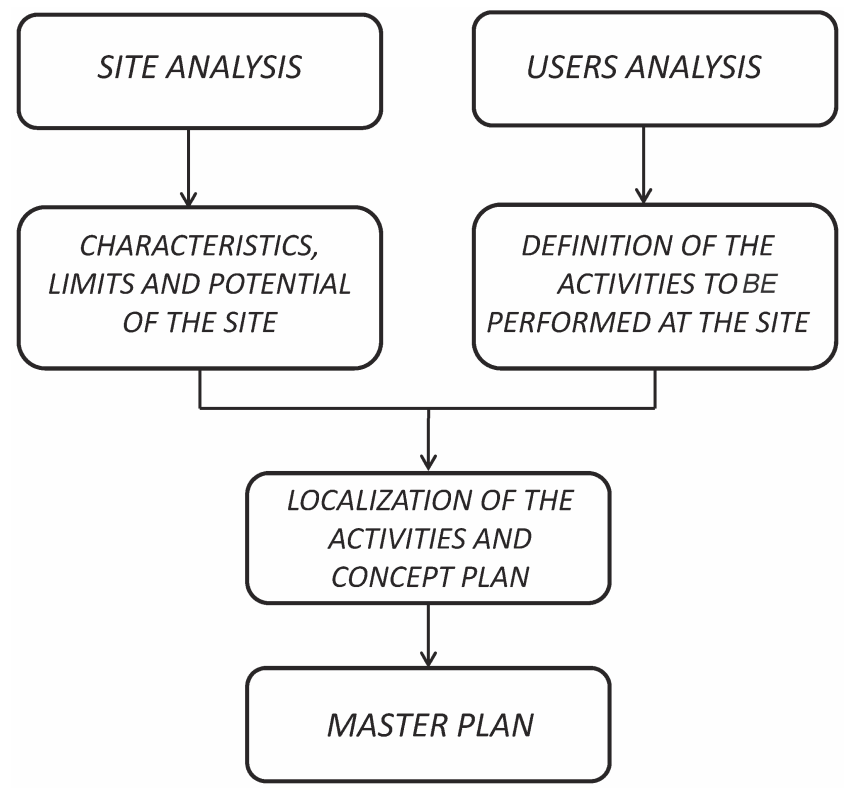

Figure 3. Methodology flowchart. 
dry summers. Rainfall is mainly concentrated in the spring and autumn, as shown in data for the period 1971-2000, recorded at Turin airport (National Civil Aviation Authority - ENAV). Annual average wind speed is less than $2 \mathrm{~m} / \mathrm{s}$, wind being predominantly from the east and northeast.

The microclimatic characteristics of the site were studied through direct observation of: shade, aspect, humidity, areas with full, partial or no sun, orography, presence of vegetation and buildings. Surveys were performed in May, June, July, at the end of August (months when the garden is most frequently used by patients), November and January, on each occasion at different times of day (10.00 am; 12.00 noon; 4.00 pm; $6.00 \mathrm{pm}$ ). During the June and January surveys, temperatures were recorded in various areas of the garden (from $10.00 \mathrm{am}$ to $2.00 \mathrm{pm}$ ).

As regards areas of shade, additional analysis was carried out using specific software (Graphisoft ArchiCad 14) to achieve shadow projections on different dates and at different times (Figure 4).

The observational analysis and the shadow projection simulation, carried out at different times of the day and in different months of the year, allowed us to perform a qualitative evaluation of the microclimatic conditions of the site in the warm and cold seasons. For the warm season (Figure 5A) the following were identified: i) zone 1: areas which are sunny for many hours of the day, protected from the wind, with low humidity; ii) zone 2: areas with sun mainly during the morning, protected from the wind; iii) zone 3 : cooler areas and areas which are more exposed to the wind.

Temperatures ranged from $21^{\circ} \mathrm{C}$ to $24^{\circ} \mathrm{C}$.

For the cold season (Figure 5B): i) zone 1: areas which are sunny for some hours of the day, protected from the wind; ii) zone 2: areas with sun during the morning, protected from the wind; iii) zone 3 : generally colder areas.

Temperatures ranged from $4^{\circ} \mathrm{C}$ to $7.5^{\circ} \mathrm{C}$.

This analysis contributed to determining the most suitable areas for outdoor activities, for example: sunny areas for orchard and horticulture; shaded and cooler areas for sports activities, walking and relaxing (in summer); windy areas as transit zones. It also facilitated the correct choice of vegetation to be planted.
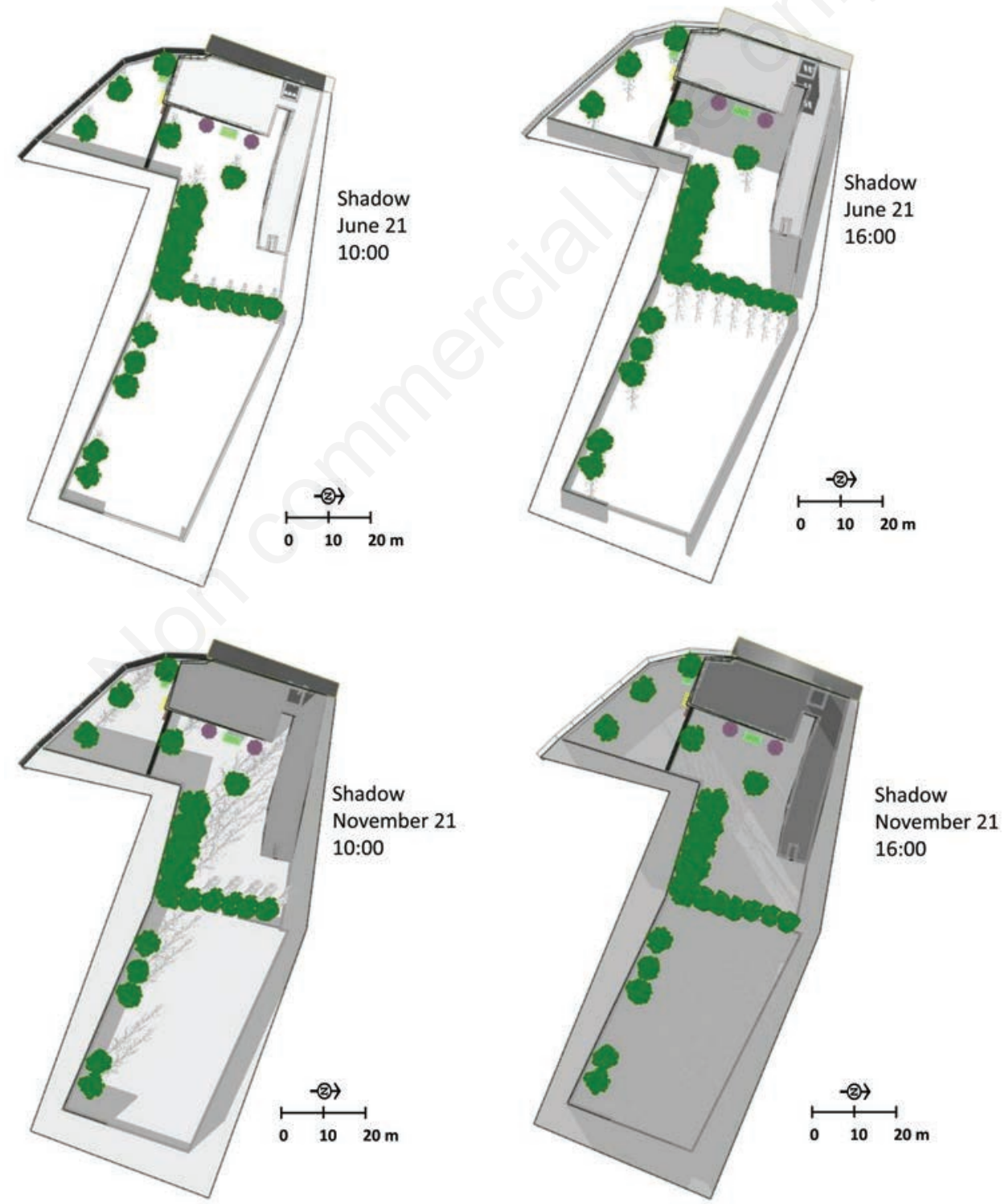

Figure 4. Shadow projection achieved using software (examples for June and November). 
With reference to land use, a survey was carried out as illustrated in Figure 6. During this phase the main problems of the area were identified as being: presence of weeds in most of the garden, poor phytosanitary state of some trees, poor condition of garden furniture; the site's potential was also evaluated, for later consideration in the design choices.

Some trees were found to have problems relating to their root systems, which should be investigated further using a modern root mapper (Ow and Sim, 2012). A row of trees (Ulmus minor Mill., a common species in many Italian cities (Pignatti, 1982; Siniscalco and Montacchini, 1994; Banfi and Galasso, 1998; Celesti Grapow et al., 2013) was found to be in good condition (Figure 5B).

\section{Analysis of users}

The aim of the analysis was to identify the needs of potential users in terms of activities in the garden, therapeutic programs, and preferred environmental conditions. Needs were investigated in two different ways: through the creation of a focus group composed of psychiatrists, psychologists and rehabilitation technicians, in order to determine real psycho-physical needs; interviews (through a questionnaire) involving a statistically-relevant sample of potential patients. This phase of the research was conducted with the approval of the clinic's Ethics Committee and in accordance with the Declaration of Helsinki (World Medical Association, 1964).

\section{Focus group}

A focus group is formed of people selected on the basis of age, social background and educational skills, who are called upon to discuss and exchange views on a specific theme (Zammuner, 2003; Albanesi, 2004; Acocella, 2008); this technique is widely used to involve people in land use policy targeting (Scott, 2011) and in the area of landscape and green area design. In this case the members of the focus group (composed of psychiatrists, psychologists and rehabilitation technicians at the clinic, together with a landscape architect) discussed the patients' needs in terms of physical and manual activities to be performed in the garden, contact with other patients and relatives, safety, privacy, risk of acute attacks.

The focus group recommended attention be paid during plan definition to some aspects related to illnesses: i) some illnesses cause disorientation: a simple structure and easily identifiable paths and entrances are required; ii) some drugs cause muscle fatigue: closely-spaced benches are required; iii) some patients cannot be exposed to the sun; iv) for some patients it is important to stimulate the senses: plants must have different colours, textures and fragrances; v) it is important to provide alternatives: sunny or shaded areas, areas for privacy or for socialisation, walking or relaxing; vi) outdoor activities should continue throughout the year, so it is important to provide covered areas (e.g., greenhouses for horticultural therapy).

Taking these considerations in account, possible activities in the garden include: physical activity and exercise, horticultural therapy, maintenance of the garden, relaxing, reading, art therapy and manual work, meeting relatives.

The focus group noted that during pauses patients often spend time with the staff. For this reason it is impossible for the staff to have a real break during lunchtime, or a cigarette break. It would therefore be appropriate to create a separate area accessible only to staff.

\section{Interviews}

The objective was to obtain feedback useful for the design process from potential users, through direct interviews (Whyte, 2001).

There are currently no patients in Villa Bianca and in any case patients change over time, so the questionnaire was submitted to a statistical sample of people hospitalized in the main Villa di Salute building.

The questionnaire contained five simple questions (in order to make it easier to compile for psychiatric patients). The first three questions cover patients' perception of the clinic garden (in order to identify positive features), while the other two concern the characteristics of, and activities desired in, a new garden.

Some technical problems were encountered in the carrying out of the interviews: firstly, the slow turnover of patients: the average number of inpatients at any one time in the clinic is 75 (maximum 81), and

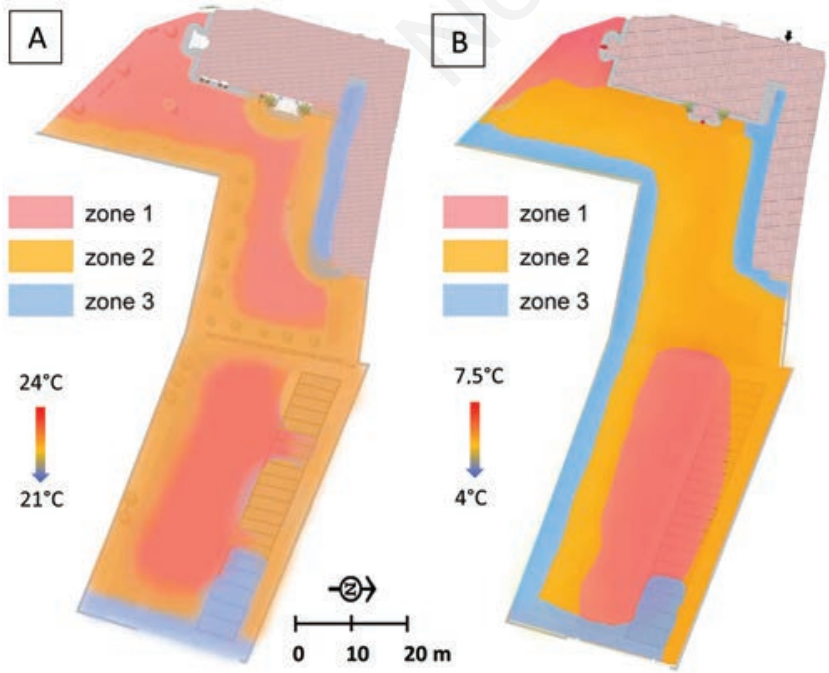

Figure 5. Microclimatic conditions: A) warm season; B) cold season.

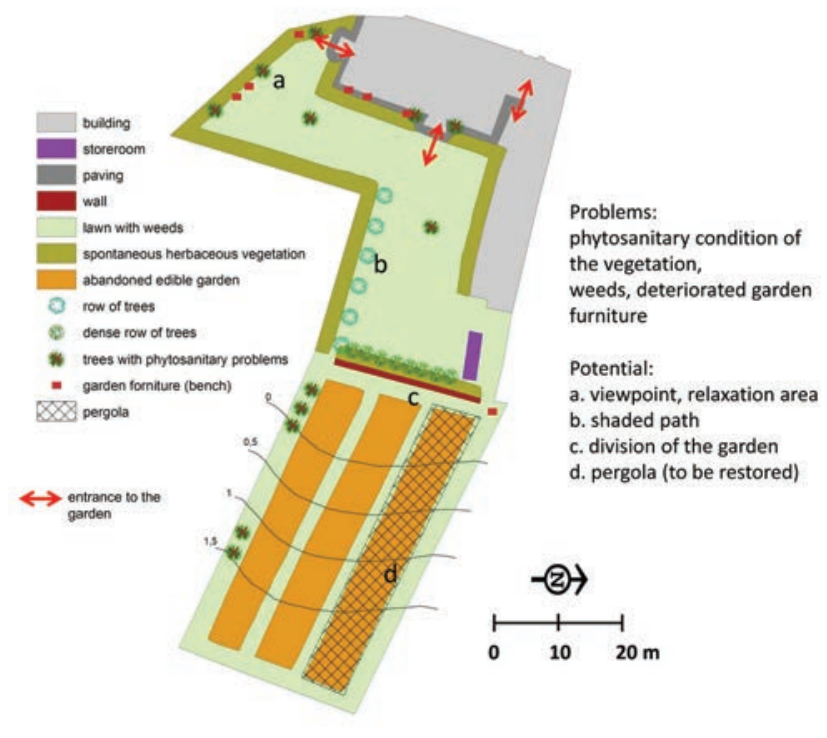

Figure 6. Land use, problems and potential. 
the average length of stay is 35 days (from a minimum of 15 days to a maximum of 3 months), so gathering data equivalent to 100 questionnaires took some months. Moreover, the confidential nature of patients' medical records had to be observed, and the clinic would not allow us to report the type of illnesses the patients who completed the questionnaire were suffering from, so no specific distinction has been made between more general preferences and preferences relating to specific illnesses (the main illnesses treated in Villa di Salute are schizophrenia and personality disorders).

We have analysed each response from the questionnaire, dividing them by respondents' age group. The questions in the questionnaire are given below.

\section{Question 1}

When you are not engaged in medical therapy or other planned activities, how much time do you spend in the garden?

A. All my free time

B. Only the time for a cigarette or a chat

C. When I have relatives or friends visiting

The majority of patients between 20 and 30 years of age and those between 51 and 60 use the garden for only a few minutes. Patients aged between 31 and 50 years of age and older patients use the garden mainly during visits by relatives, from 1.30 to $2.30 \mathrm{pm}$ (Monday-Friday) and from 2.30 to $6.00 \mathrm{pm}$ (Saturday and Sunday). There are no restrictions on the number of relatives admitted, although there are usually one or two per patient. For this reason in the design phase it is important to provide facilities to accommodate visitors and patients.

\section{Question 2}

What kind of feelings do you have when you are in the garden?

A. Positive (tranquillity, relaxation)

B. Negative (loneliness, abandonment)

C. No special feeling

Most patients have positive feelings but some experience loneliness. It is important to provide quiet areas for privacy but also areas for socialising.

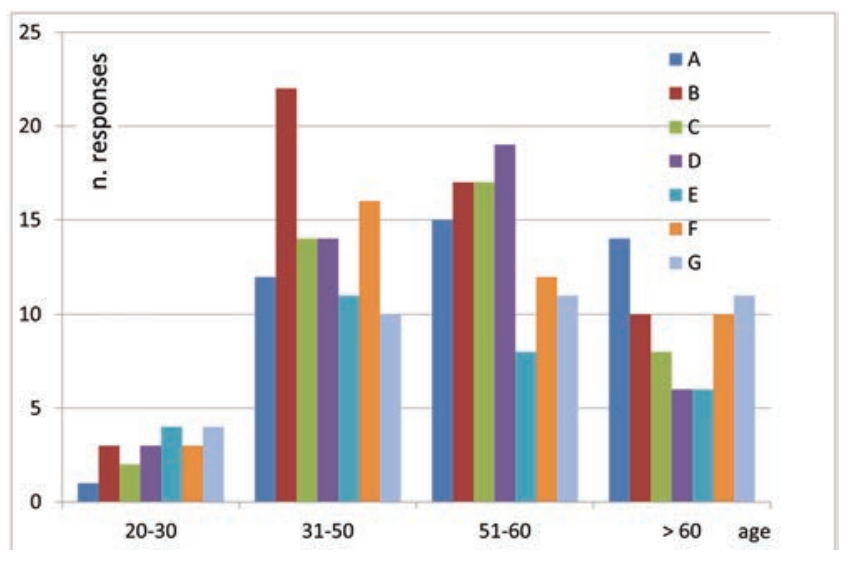

Figure 7. Question 5: suggested improvements.

\section{Question 3}

What do you think is the most pleasing feature of the garden? (several choices possible)

\section{A. Seeing plants and flowers}

B. Smells and sounds of nature (wind rustling, birds chirping, ...)

C. The possibility of being outdoors

D. The light and warmth of the sun

E. The sense of peace

The majority of patients enjoy the chance to be outdoors. At present the planned activities performed in the garden under staff supervision are board games, card games, table tennis and football, and the garden is mainly used for meeting relatives. The design must contemplate the possibility of transferring other rehabilitation activities and related facilities into the garden.

\section{Question 4}

Would you like to do any activities in the new garden other than those already available? (several choices possible)

A. Taking long walks

B. Physical exercise outdoors

C. Having quiet areas to sit and read away from noise

D. Growing flowers

E. Growing vegetables

F. Having quiet areas to chat with relatives and friends

Many patients would like to walk, grow flowers and plants and have secluded areas for talking with relatives.

\section{Question 5}

What improvements would you make in a new garden compared with the current one? (several choices possible)

A. Make flowerbeds

B. Increase the space available for walking

C. Increase seating

D. Eliminate perimeter wall

E. Create lawn areas for sitting or lying down, and for walking barefoot

F. Create an area with water (a fountain or a pond with fish and aquatic plants)

G. Include an area for small animals (an aviary with birds, an area

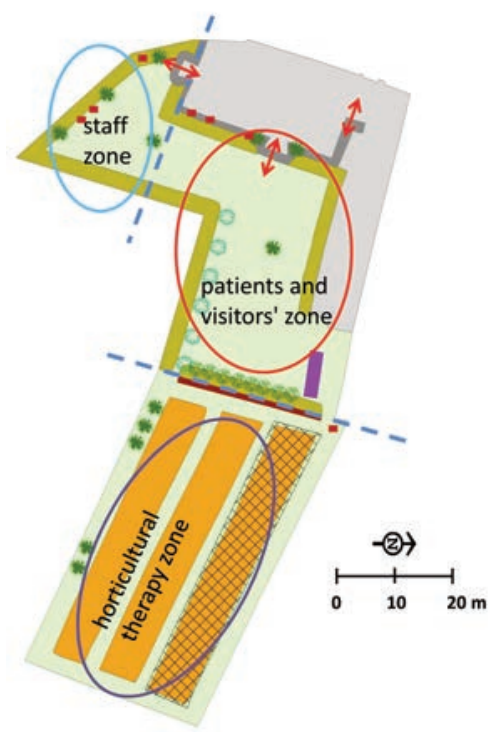

Figure 8. Subdivision of the garden in three main zones. 
for dogs or cats, a fishpond). In accordance with the needs of the patients, ornamental and quiet areas, footpaths, areas for growing flowers and areas for private talks should be planned (Figure 7).

\section{Results}

Decisions based on the results of the previous analysis were made for the planning of the healing garden in stages: identification of the activities to be carried out and requirements; localisation of the activities in the garden and a concept plan; definition of the healing garden master plan.

\section{Definition of activities in the garden}

In this phase the activities to be carried out in the new garden of Villa Bianca were defined, taking into account the outcomes of the focus group survey and the interviews. The following activities were identified: relaxing, physical activity, rehabilitation activities (manual work, board games, art therapy, etc.), horticultural therapy, eating outdoors, meeting relatives, cigarette breaks.

Table 1 shows the activities to be performed and the users involved (in terms of type, average number, time required, square meters/person needed) in spring-summer and autumn-winter; Table 2 shows the activities related to required features and any required facilities, buildings, garden furniture.

Table 1. Garden activities: users involved (estimated), time of use, required $\mathrm{m}^{2} /$ person.

\begin{tabular}{|c|c|c|c|c|c|}
\hline & Users involved & Patients (N) & Staff (N) & Hours & Area (m²/person) \\
\hline \multicolumn{6}{|c|}{ Spring-Summer } \\
\hline \multicolumn{6}{|l|}{ Group activities } \\
\hline Physical activity & Patients-staff* & 15 & 2 & $9.00-11.00 \mathrm{am}$ & 4 \\
\hline Rehabilitation activities & Patients-staff* & 15 & 4 & $4.00-6.00 \mathrm{pm}$ & 1.5 \\
\hline Horticultural therapy & Patients-staff* & 15 & 3 & $9.00-11.00 \mathrm{am}$ & 10 \\
\hline Eating outdoors & Patients-staff* & 15 & 3 & $12.00-1.00 \mathrm{pm}$ & $1.2-1.5$ \\
\hline \multicolumn{6}{|l|}{ Individual activities } \\
\hline Relaxing & Patients & 15 & 2 & $9.00 \mathrm{am}-7.00 \mathrm{pm}$ & 2 \\
\hline Relaxing & Staff & 9 & - & $9.00 \mathrm{am}-7.00 \mathrm{pm}$ & 2 \\
\hline Meeting relatives & Patients-relatives & 15 & - & $1.30-2.30 \mathrm{pm}^{\circ}$ & 2 \\
\hline Cigarette break & Patients & 6 & 2 & $8.00 \mathrm{am}-9.00 \mathrm{pm}$ & 2.5 \\
\hline Cigarette break & Staff & 4 & - & $8.00 \mathrm{am}-9.00 \mathrm{pm}$ & 2.5 \\
\hline Physical activity & Patients & 6 & 2 & $9.00-11.00 \mathrm{am}$ & 12 \\
\hline Eating outdoors & Staff & 9 & - & $12.00-2.00 \mathrm{pm}$ & $1.2-1.5$ \\
\hline
\end{tabular}

Autumn-Winter

\begin{tabular}{llllll}
$\begin{array}{l}\text { Group activities } \\
\text { Horticultural therapy }\end{array}$ & Patients-staff* \\
Individual activities & Patients & 15 & 3 & $9.00-11.00$ am & $7-8$ (greenhouse) \\
Relaxing & Staff & 15 & 2 & 9.00 am-7.00 pm & 2 \\
Relaxing & Patients & 9 & - & 9.00 am- $7.00 \mathrm{pm}$ & 2 \\
Cigarette break & Staff & 6 & 2 & 8.00 am- $9.00 \mathrm{pm}$ & 2.5 \\
Cigarette break & Patients & 4 & - & $8.00 \mathrm{am}-9.00 \mathrm{pm}$ & 2.5 \\
Physical activity & 3 & 1 & $3.00-4.00 \mathrm{pm}$ & 12 \\
\hline
\end{tabular}

*At the same time and in the same areas; ${ }^{\circ} .00 \mathrm{pm}$ on Saturdays or Sundays.

Table 2. Garden activities related to required features and facilities.

\begin{tabular}{|c|c|c|}
\hline Activities & Required features & Facilities \\
\hline Relaxing & $\begin{array}{l}\text { Quiet; privacy; within sight and under control of staff; protected from wind; } \\
\text { shade and cool in summer }\end{array}$ & Benches; pergola; waste bins \\
\hline Physical activity & $\begin{array}{l}\text { Within sight and under control of staff; cool in summer; } \\
\text { suitable distance from smoking area }\end{array}$ & Outdoor gym equipment \\
\hline Rehabilitation activities & Within sight and under control of staff; protected from wind; shade in summer & Tables; benches; chairs; awning; waste bins \\
\hline Horticultural therapy & $\begin{array}{l}\text { Separate area; sunny; within sight and under control of staff, near to storeroom; } \\
\text { partially covered (for winter activities); partially adapted for elderly } \\
\text { and disabled (raised flowerbeds) }\end{array}$ & $\begin{array}{l}\text { Storeroom with tools and supplies; irrigation } \\
\text { system; greenhouse; raised flowerbeds; } \\
\text { benches; organic waste container }\end{array}$ \\
\hline Easting outdoors & $\begin{array}{l}\text { Quiet; within sight and under control of staff; protected from wind; } \\
\text { shade in summer, not far from building }\end{array}$ & Tables; chairs; awning \\
\hline Meeting relatives & Quiet; seclusion; shade in summer, not far from building & Benches; pergola; waste bins \\
\hline Cigarette break & Protected from rain; suitable distance from eating and relaxing areas & Awning; benches; ashtray; waste bins \\
\hline
\end{tabular}




\section{Concept plan}

During the first phase three main zones were identified according to user types (Figure 8): i) zone for staff activities, with access restricted to the employees of the clinic, and having a separate entrance from the building $\left(440 \mathrm{~m}^{2}\right)$; ii) zone for patients and visitors where people can move independently in sight of the staff $\left(1100 \mathrm{~m}^{2}\right)$; iii) zone reserved for patients and staff for horticultural therapy $\left(2970 \mathrm{~m}^{2}\right)$.

During the next step different areas were identified for the planned activities (concept plan), taking into account land use (Figure 6), and the characteristics and requirements listed in Tables 1 and 2 . Areas for having lunch, smoking, and relaxing (enhanced by a viewpoint), as well as a flowerbed with ornamental plants, were defined within the staff zone. Areas for physical activity, relaxing, smoking, meeting relatives and having lunch were defined within the patients and visitors' zone. Areas for horticultural therapy (partly covered) and resting were planned in the remaining zone (Figure 9).

\section{Healing garden master plan}

The aim of the garden master plan was to define the works to be carried out and equipment to be installed and their location. The master plan is the preliminary version of the project to be discussed with the client, and precedes the executive project (Figures 10 and 11).

According to the garden subdivision as illustrated in Figure 8, the works planned are as follows:

- Staff zone: planting of two trees (Ulmus minor) and installation of four benches to create a relaxation area enhanced by a panoramic view of the hills; partial paving of the zone $\left(120 \mathrm{~m}^{2}\right)$ and construction of a covered smoking area, as well as a covered dining area with tables and chairs $\left(20 \mathrm{~m}^{2}\right)$; creation of two flowerbeds with herbs such as Ocimum basilicum L., Rosmarinus officinalis L., Petroselinum crispum (Mill.) Fuss, Origanum majorana L., Mentha $x$ piperita $\mathrm{L}$., Thymus vulgaris $\mathrm{L}$; installation of wooden planters with small trees and evergreen ornamental shrubs (Steven, 1994; Pizzetti, 2004; Thekkayam, 2009), in order to hide the concrete boundary wall, and benches for sitting on and resting (Figure 12 shows the layout, species used, and the colours in the different seasons).

- Patients and visitors' zone: paving of a large section ( $\left.600 \mathrm{~m}^{2}\right)$; construction of a covered smoking area $\left(10 \mathrm{~m}^{2}\right)$; creation of a covered area for physical activity $\left(70 \mathrm{~m}^{2}\right)$; installation of a pergola with tables and chairs to create a multifunctional area for lunch, manual work, board games $\left(40 \mathrm{~m}^{2}\right)$, installation of pergolas covered with plant material (Wisteria sinesis (Sims) Sweet) and seats for receiving visitors, maintenance of the existing rows of trees (Ulmus minor) in an area which is suitable for walking and running; realisation of raised flowerbed to facilitate horticultural activities for the elderly and the renovation of an existing building as a storeroom; elimination of weeds and vegetation with phytosanitary problems; planting of two trees (Ulmus minor) and installation of two benches in a relaxation area.

- Horticultural therapy zone: renovation of the existing wall (h $1.2 \mathrm{~m}$ ) to separate the zone from the rest of the garden; renovation of the existing pergola (h $2.7 \mathrm{~m}$ ) covered with Actinidia kolomikta (Rupr. et Maxim) Maxim and Vitis vinifera $\mathrm{L}$. and creation of a relaxation area with benches and flowerbeds; realisation of an edible garden for horticultural therapy and greenhouses for winter activities; planting of an orchard of Prunus persica (L.) Batsch, Prunus domestica L. and Pyrus communis L.

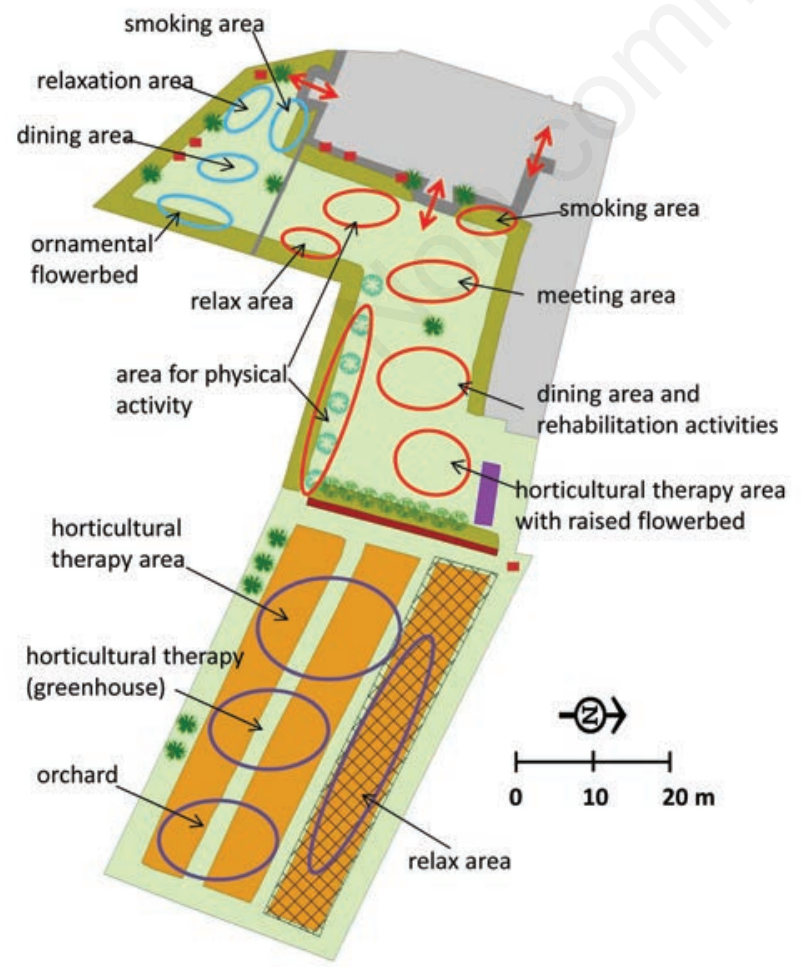

Figure 9. Concept plan.

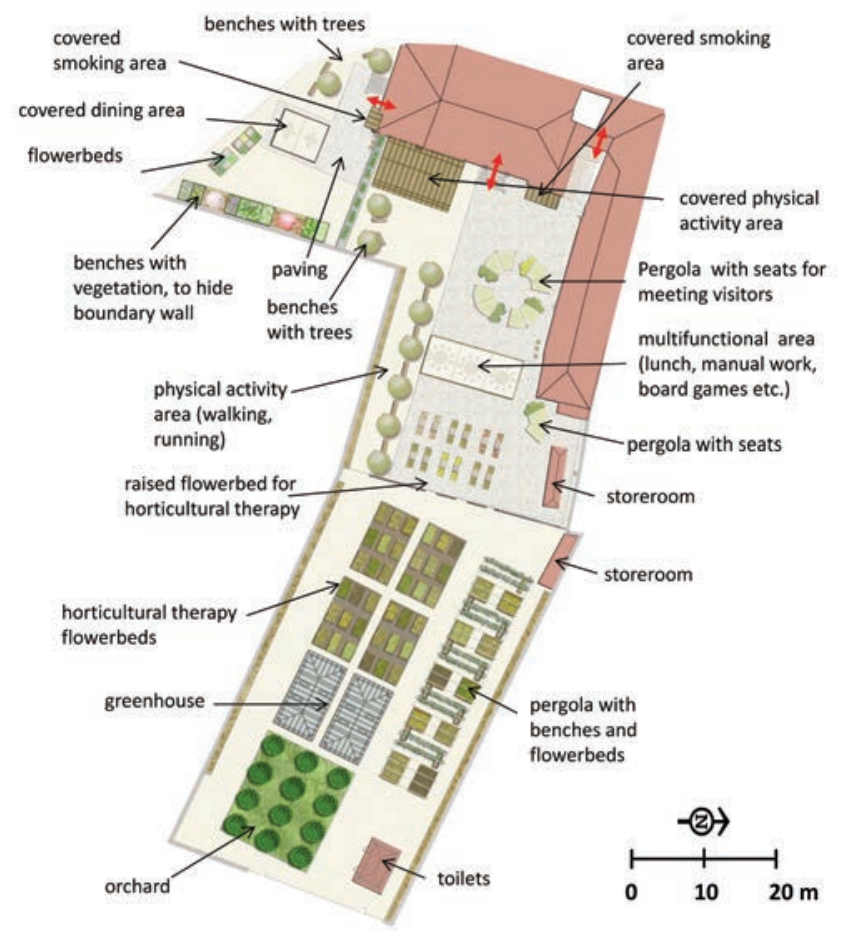

Figure 10. Master plan. 


\section{Considerations and conclusions}

The designing of green healing areas requires consideration of some key issues such as: contact with nature, patient autonomy and ease of orientation, patient safety and comfort, possibility of choosing between places and functions, family atmosphere.

- Contact with nature. The patient must experience contact with nature through his/her senses (seeing different colours, touching plants and small animals if possible, hearing the sounds of nature, smelling the flowers and tasting fruits and vegetables). In this sense the choice of appropriate vegetation is important, with preference for perennial and easy-to-maintain plants of different colours, smells and textures to stimulate senses, flowering in different periods of the year, without toxic or stinging elements. The choices made for the area studied reflect these characteristics.

- Patients' autonomy and ease of orientation. The need for autonomy is one of the major stress factors for patients and guests in care homes (Malkin, 1992). The ability to move independently in the garden can be promoted in various ways: clearly visible paths, signs, landmarks, visibility of access to the building.

- Patients' safety and comfort. Safety and comfort can be increased through a careful design of details such as suitable furniture, the

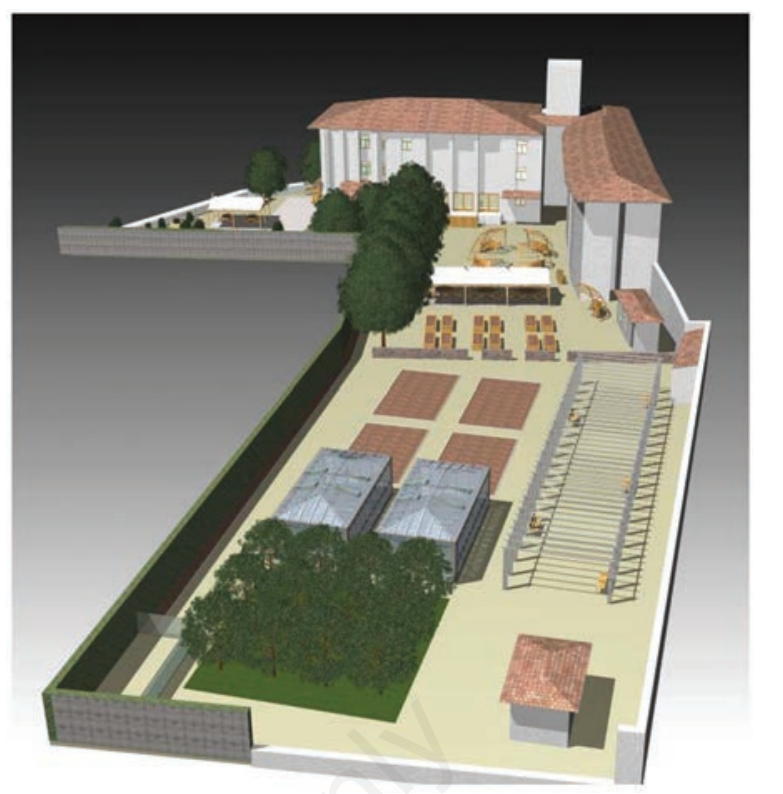

Figure 11. Master plan: rendering.

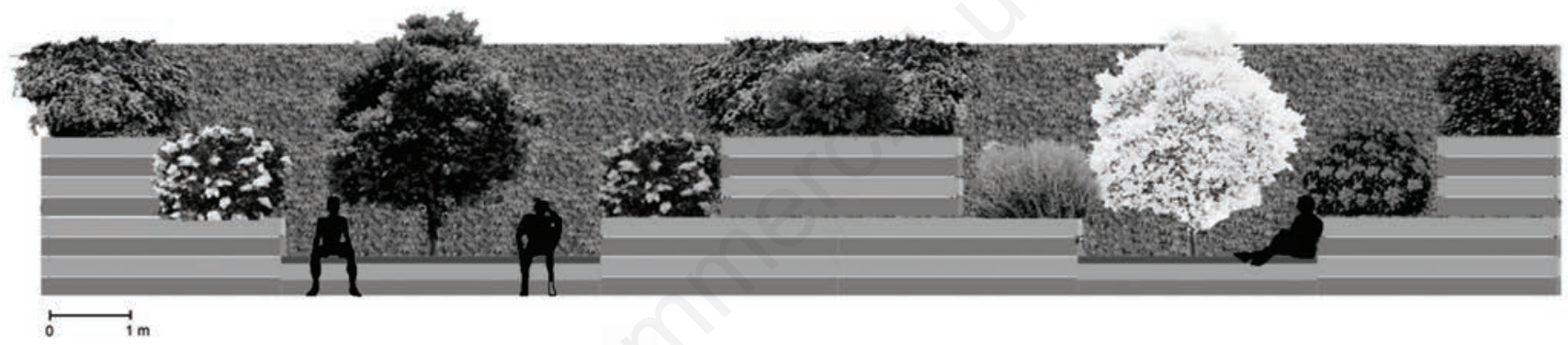

TREES
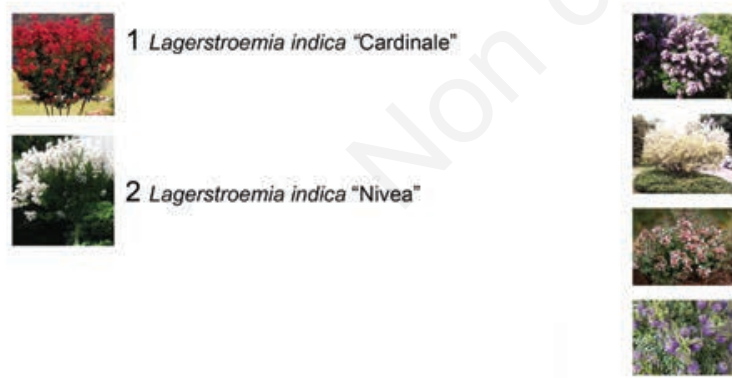

3 Syringa vulgaris "Cora Brandt"

4 Exochorda racemosa

5 Abelia grandiffora

6 Hebe variegate
SHRUBS

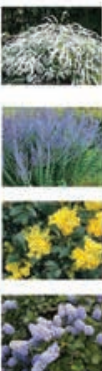

7 Spirea arguta

8 Perovskia atriplicifolia "Blue Spire"

9 Mahonia aquifolium "Apollo"

10 Ceanothus thyrsifforus
SPRING - main colors

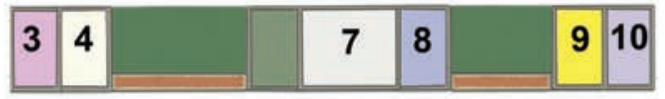

AUTUMN - main colors

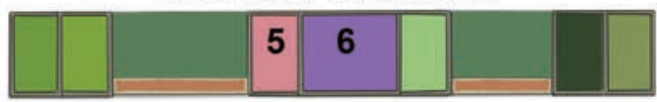

SUMMER - main colors

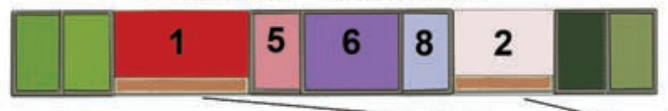

WINTER - main colors

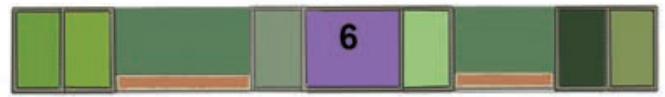

Figure 12. Distribution of wooden planters, benches, plants and colours in different seasons. 
choice of flooring, the presence of handrails, the absence of barriers along paths, the use of protection (from sun or rain) and, as mentioned above, not using vegetation which can harm patients.

- Possibility of choosing between places and functions. Having a choice is very important for a patient from the psychological point of view; in the garden it is important to provide areas with different functions where different activities are carried out, and to allow the patient to choose between sunny or shaded, quiet and busy areas.

- Family atmosphere. Design can help in maintaining a family atmosphere in the garden, limiting separation from familiar things and through the creation of shared spaces and meeting areas.

In conclusion, it is desirable that the process of the design of healing gardens refers to the scientific evidence from environmental psychology and neuroscience (evidence-based design) (Senes and Toccolini, 2013), just as it is important, after the completion of the project, to assess whether the objectives have been achieved. With reference to the case study, the proposed project includes the use of the garden not only for relaxation, but also for active exploitation through the practice of horticulture. The proposed methodology can be applied to similar situations, although different types of patients may require different design choices, based on their needs as identified by both experts (focus groups) and the users themselves. Design choices, and materials, furniture and vegetation utilized, aim at ensuring patient safety, comfort, autonomy and freedom of choice. After the creation of the garden an evaluation of the project should be carried out, to verify its effectiveness from a therapeutic point of view.

\section{References}

Acocella I. 2008. Il focus group Teoria e pratica. Franco Angeli, Milano, Italy.

Adevi A.A., Lieberg M. 2012. Stress rehabilitation through garden therapy. A caregiver perspective. Urban Forest. Urban Green. 11:51-8.

Albanesi C. 2004. I focus group. Carocci Editore, Roma, Italy.

Banfi E., Galasso G. 1998. La flora spontanea della città di Milano alle soglie del terzo millennio e i suoi cambiamenti a partire dal 1700 . Società Italiana di Scienze Naturali, Museo civico di Storia Naturale, Milano, Italy.

Beer A. 2000. Environmental planning for site development. E. \& F. N. Spon, London, UK.

Borghi C. 2007. Il giardino che cura. Il contatto con la natura per ritrovare la salute e migliorare la qualità della vita. Giunti, Milano, Italy.

Borghi C. 2011. Un giardino per stare bene. Perché il giardino ci regala la salute e come progettarlo. Apogeo, Milano, Italy.

Celesti Grapow L., Capotorti G., Del Vico E., Lattanzi E., Tilia A. Blasi C. 2013. The vascular flora of Rome. Plant Biosyst. 147:4.

Cohen Mansfield J., Werner P. 1998. The effects of an enhanced environment on nursing home residents who pace. Gerontologist. 38:199-208.

Cooper Marcus C. 2005a. Healing havens. Landscape Architecture. 95:85-9.

Cooper Marcus C. 2005b. No ordinary garden. Alzheimer's and other patients find refuge in a Michigan dementia-care facility. Landscape Architecture. 95:26-39.

Cooper Marcus C. 2007. Healing gardens in hospitals. IDRP Interdisciplin. Design Res. e-J. 1:1. Availble from: http://spokane. wsu.edu/academics/Design/IDRP2/Nol_1/Cooper_Marcus.pdf

Cooper Marcus C., Barnes M. 1995. Gardens in healthcare facilities: uses, therapeutic benefits and design recommendations. The
Center for Health Design Inc., Martinez, CA, USA.

Küller R., Wetterberg L. 1996. The subterranean work environment: impact on wellbeing and health. Environ. Int. 22:33-52.

Malkin J. 1992. Hospital interior architecture: creating healing environments for special patient populations. John Wiley \& Sons, New York, NY, USA.

Namazi K.H., Johnson B.D. 1992. Pertinent autonomy for residents with dementias: Modification of the physical environment to enhance independence. Am. J. Alzheim. Dis. Other Demen. 7:16-21.

Ow L.F., Sim E.K. 2012. Detection of urban tree roots with the ground penetrating radar. Plant Biosyst. 146:288-97.

Pignatti S.1982. Flora d'Italia. Edagricole, Bologna, Italy.

Pizzetti I. 2004. Fiori e giardino. Garzanti, Milano, Italy.

Rodiek S. 2002. Influence of an outdoor garden on mood and stress in older persons. J. Ther. Hortic. 8:13-21.

Scott A. 2011. Focussing in on focus groups: effective participative tools or cheap fixes for land use policy?. Land Use Policy. 28:684-94.

Seifert P., Hickman D. 2005. Enhancing patient safety in a healing environment. Topics Adv. Practice Nurs. J. 5:1-7.

Senes G, Toccolini A. 2013. Healing garden: le aree verdi per il benessere dell'uomo. In: M.C. Zerbi, M.A. Breda (eds.), Rinverdiamo la città: parchi orti e giardini. Giappichelli, Torino, Italy, pp 65-88.

Sherman S.A., Varni J.W., Ulrich R.S., Malcarne V.L. 2005. Post-occupancy evaluation of healing gardens in a pediatric cancer center. Landscape Urban Plann. 73:167-83.

Siniscalco C., Montacchini F. 1994. Prodromo della flora urbica torinese. Allionia. 32:137-61.

Steven M.S. 1994. Manual of herbaceous ornamental plants. Stipes publishing L.L.C., Champaign, IL, USA.

Stigsdotter U.A., Grahn P. 2002. What makes a garden a healing garden?. J. Ther. Hortic. 13:60-9.

Stigsdotter U.A., Grahn P. 2003. Experiencing a garden: a healing garden for people suffering from burnout diseases. J. Ther. Hortic. 14:39-48.

Thekkayam S.G. 2009. Ornamental plants. New India Publishing Agency, New Delhi, India.

Ulrich R.S. 2001. Effects of healthcare environmental design on medical outcomes. pp 49-59 in Proc. 2nd Int. Conf. on Health and Design, Stockholm, Sweden.

Ulrich R.S. 2002. Communicating with the healthcare community about plant benefits. Proc. 6th Int. People Plant Symposium, Chicago Botanic Garden, Chicago, IL, USA.

Ulrich R.S., Simons R.F., Losito B.D., Fiorito E., Miles M.A., Zelson M. 1991. Stress recovery during exposure to natural and urban environments. J. Environ. Psychol. 11:201-30.

Van Den Berg A.E., Custers M.H. 2011. Gardening promotes neuroendocrine and affective restoration from stress. J. Health Psychol. 16:3-11.

Varni J.W., Burwinkle T.M., Dickinson P., Sherman S.A., Dixon P., Ervice J.A., Leydenp A., Sadler B.L. 2004. Evaluation of the built environment at a children's convalescent hospital: development of the pediatric quality of life inventory (TM) parent and staff satisfaction measures for pediatric health care facilities. J. Develop. Behav. Pediatrics 25:10-20.

Whyte W.H. 2001. The social life of small urban spaces. Project for Public Spaces Inc., New York, NY, USA.

World Medical Association. 1964. Declaration of Helsinki - Ethical principles for medical research involving human subjects (amendends 1975, 1983, 1989, 1996, 2000, 2002, 2004, 2008, 2013).

Zammuner V.L. 2003. I focus group. Il Mulino, Bologna, Italy. 